\title{
Endovascular treatment of unruptured aneurysms of cavernous and ophthalmic segment of internal carotid artery with flow diverter device Pipeline
}

\author{
Marko Jevsek ${ }^{1}$, Charbel Mounayer ${ }^{2}$, Tomaz Seruga ${ }^{1}$ \\ ${ }^{1}$ Department of Radiology, University Clinical Center Maribor, Slovenia \\ ${ }^{2}$ Department of Radiology, Dupuytren University Hospital, France
}

Radiol Oncol 2016

Received 22 January 2016

Accepted 23 August 2016

Correspondence to: Tomaž Šeruga, M.D., Ph.D., Department of Radiology, University Clinical Center Maribor, Ljubljanska 5, 2000 Maribor, Slovenia. Phone: +386232122 56; E-mail: ttseruga@gmail.com

Disclosure: No potential conflicts of interest were disclosed.

\begin{abstract}
Background. Intra-arterial treatment of aneurysms by redirecting blood flow is a newer method. The redirection is based on a significantly more densely braided wire stent. The stent wall keeps the blood in the lumen of the stent and slows down the turbulent flow in the aneurysms. Stagnation of blood in the aneurysm sac leads to the formation of thrombus and subsequent exclusion of the aneurysm from the circulation. The aim of the study was to evaluate flow diverter device Pipeline for broad neck and giant aneurysm treatment.

Methods. Fifteen patients with discovered aneurysm of the internal carotid artery were treated between November 2010 and February 2014. The majority of aneurysms of the internal carotid artery were located intradural at the ophthalmic part of the artery. The patients were treated using a flow diverter device Pipeline, which was placed over the aneurysm neck. Treatment success was assessed clinically and angiographically using O'Kelly Marotta scale.

Results. Control angiography immediately after the release of the stent showed stagnation of the blood flow in the aneurysm sac. In none of the patients procedural and periprocedural complications were observed. 6 months after the procedure, control CT or MR angiography showed in almost all cases exclusion of the aneurysm from the circulation and normal blood flow in the treated artery. Neurological status six months after the procedure was normal in all patients.

Conclusions. Treatment of aneurysms with flow diverter Pipeline device is a safe and significantly less time consuming method in comparison with standard techniques. This new method is a promising approach in treatment of broad neck aneurysms.
\end{abstract}

Key words: flow diversion; Pipeline; aneurysm; ophthalmic segment

\section{Introduction}

Surgical craniotomy was the only possible treatment of brain vessels aneurysms in the past. First surgical procedures started in the early 1990s.

Intra-arterial embolization treatment of aneurysms with electrolytically detachable coils came into clinical use in 1994, when Guido Guglielmi introduced his invention. ${ }^{1}$

Within few years endovascular treatment became a popular method equivalent to surgery.
ISAT study was the first large-scale randomized comparative study of endovascular and surgical treatment of ruptured cerebral aneurysms. ${ }^{2}$ Results of the study showed that endovascular therapy is safer and more effective in comparison with surgery. The study also showed that endovascular treatment improves survival. The consequence of the study was a re-thinking in the approach of the treatment of these cerebral vascular diseases.

The only disadvantage of the endovascular treatment was the appearance of the recanali- 
zation of the aneurysm. Different studies have shown that this can occur in 10 to $15 \%$, even $25 \%$ in some studies. ${ }^{3,4}$ Recanalization rate was higher in the aneurysm with a wider neck and in complex aneurysms. With the introduction of stents and supporting balloons the percentage of recanalization of the wide neck aneurysms decreased significantly. 5,6

Attempts were also made with a non-adhesive liquid embolic agent Onyx (ev3, Covidien, USA) and balloon remodeling. Onyx consists of a solution of $20 \%$ ethylene vinyl alcohol copolymer dissolved in dimethyl sulfoxide, to which tantalum powder is added. Tantalum powder ensures radiopaque appearance under the fluoroscopy.

There still remained a problem with the complex and gigantic aneurysms. Finding a solution for the treatment of such type of aneurysms has led to the development of a new generation of stents which are densely braided and which retain most of the blood flow within the lumen of the stent. This results in the diversion of the blood flow in the aneurysmatic sac and its slowing down which leads to the formation of a thrombus and subsequent scarification of the thrombus. ${ }^{7}$ At the end of this process, the aneurysm is completely excluded from the circulation. ${ }^{8,9}$ This method was used only in the cavernous sinus and the ophthalmic part of the internal carotid artery at first, but nowadays these stents are also used for the more narrow, distal A1 and M1 segments of the cerebral arteries. They are also useful for the treatment of small blister aneurysms, which are, due to their small size, unsuitable for the embolization with coils. ${ }^{10}$

Indications for the use of flow diverting device are still in the formation stage. Also the method itself is not yet fully defined. ${ }^{11}$ Flow diverting device is most commonly used alone. It can be also used in combination with another flow diverting device or in combination with coils, which are inserted into the aneurysm prior to the deployment of the stent. These coils should foster the formation of the thrombus, as well as protect against a possible aneurysm rupture.

TABLE 1. Patients by age, size and position of an aneurysm, complications, and follow-up

\begin{tabular}{|c|c|c|c|c|c|c|c|c|}
\hline $\begin{array}{l}\text { No/Age } \\
\text { (years)/ } \\
\text { Gender }\end{array}$ & $\begin{array}{l}\text { Clinical } \\
\text { presentation }\end{array}$ & Location & Type & $\begin{array}{l}\text { Size }(\mathrm{mm}) / \\
\text { Neck }(\mathrm{mm})\end{array}$ & $\begin{array}{l}\text { Dilatation of the } \\
\text { stent with the } \\
\text { PTA balloon }\end{array}$ & $\begin{array}{l}\text { Late clini- } \\
\text { cal com- } \\
\text { plications }\end{array}$ & $\begin{array}{l}\text { Type of control to } \\
\text { confirm closure/ } \\
\text { Status (month) }\end{array}$ & $\begin{array}{l}\text { OKM } \\
\text { Scale }\end{array}$ \\
\hline $\begin{array}{l}1 / 57 / \\
\text { Female }\end{array}$ & $\begin{array}{l}\text { Mass effect } \\
\text { (vision loss) }\end{array}$ & Parophthalmic & S & $12 / 5$ & - & - & CTA/Complete (3) & C3 \\
\hline $\begin{array}{l}3 / 55 / \\
\text { Female }\end{array}$ & $\begin{array}{l}\text { Recurrent (coil) } \\
\text { incidental } \\
\text { (headache) }\end{array}$ & Parophthalmic & $S$ & $5 / 3$ & - & - & CTA/ Complete (5) & B3 \\
\hline $\begin{array}{l}5 / 62 / \\
\text { Female }\end{array}$ & $\begin{array}{l}\text { Incidental } \\
\text { (headache) }\end{array}$ & ICA - PCOM & $S$ & $6 / 6$ & - & - & CTA/ Complete (2) & $D$ \\
\hline $\begin{array}{l}\text { 6/57/ } \\
\text { Female }\end{array}$ & $\begin{array}{l}\text { Mass effect } \\
\text { (vision loss) }\end{array}$ & Carotid-cavernous & $S$ & $7 / 4$ & - & - & CTA/ Complete (1) & $D$ \\
\hline $\begin{array}{l}7 / 56 / \\
\text { Female }\end{array}$ & $\begin{array}{l}\text { Mass effect } \\
\text { (diplopia) }\end{array}$ & Parophthalmic & $S$ & $12 / 7$ & PTA & - & CTA/ Complete (3) & $\mathrm{C} 2$ \\
\hline $\begin{array}{l}\text { 10/52/ } \\
\text { Female }\end{array}$ & $\begin{array}{l}\text { Mass effect } \\
\text { (diplopia) }\end{array}$ & ICA - PCOM & $S$ & $23 / 9$ & - & - & MRA / Complete (6) & B3 \\
\hline $\begin{array}{l}11 / 52 / \\
\text { Female }\end{array}$ & $\begin{array}{l}\text { Mass effect } \\
\text { (diplopia) }\end{array}$ & Parophthalmic & $S$ & $20 / 3$ & - & - & DSA/ Complete (3) & $\mathrm{C} 2$ \\
\hline $\begin{array}{l}\text { 12/55/ } \\
\text { Female }\end{array}$ & $\begin{array}{l}\text { Mass effect } \\
\text { (diplopia) }\end{array}$ & Parophthalmic & S & $22 / 5$ & PTA & - & MRA/Complete (6) & $\mathrm{Cl}$ \\
\hline $\begin{array}{l}\text { 13/47/ } \\
\text { Female }\end{array}$ & $\begin{array}{l}\text { Incidental } \\
\text { (headache) }\end{array}$ & ICA - PCOM & S & $4 / 3$ & - & - & DSA/Complete (3) & C3 \\
\hline $\begin{array}{l}14 / 54 / \\
\text { Male }\end{array}$ & $\begin{array}{l}\text { Recurrent } \\
\text { aneurysm (clip) } \\
\text { (headache) }\end{array}$ & ICA - cisternal & $\mathrm{F}$ & $16 / 14$ & - & - & MRA/Complete (6) & B2 \\
\hline $\begin{array}{l}15 / 28 / \\
\text { Male }\end{array}$ & $\begin{array}{l}\text { Incidental } \\
\text { (headache) }\end{array}$ & Ml & S & $6 / 5$ & - & - & MRA/Complete (6) & B3 \\
\hline
\end{tabular}

CTA = computed tomography angiography; DSA = digital subtraction angiography; ICA = internal carotid artery; $M R A=$ magnetic resonance angiography; OKM = O'KellyMarotta; PCOM = posterior communicating artery, PTA = percutaneous transluminal angioplasty 


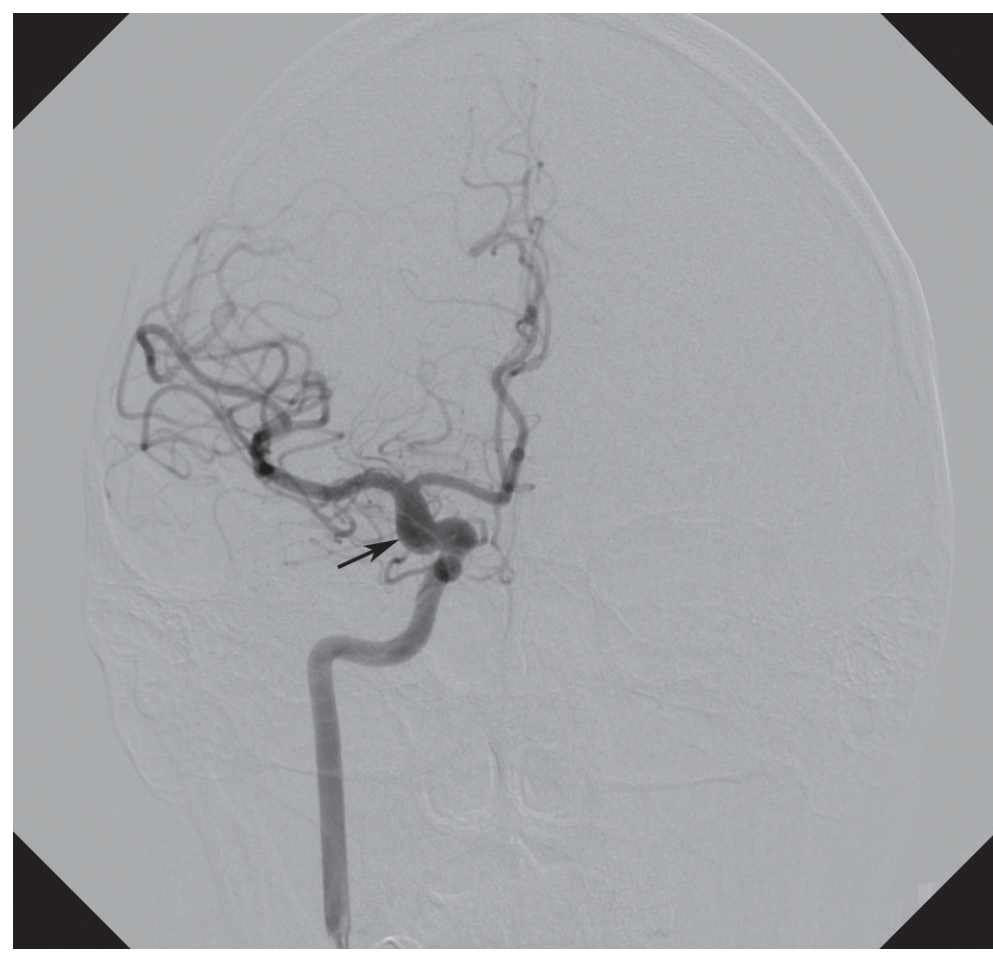

FIGURE 1. A fusiform aneurism of the internal carotid artery is indicated by the arrow.

The aim of the study was to evaluate flow diverter device Pipeline for broad neck and giant aneurysm treatment.

\section{Patients and methods}

\section{Patients and study design}

Fifteen patients were treated with a flow diverting device in our institution so far. Average age was 50.9 years (range 22-72). There were 13 female and 2 male patients. The procedures were carried out between November 2010 and February 2014. The procedures described in this study were in accordance with the Helsinki declaration. All patients gave their written informed consent before being included in the present study. This study was approved by the National Ethics Committee (No. 145/02/0).

All aneurysms were discovered accidentally or as part of the diagnostic process for headaches, visual disturbances or clinical symptoms of mass effect. None of the patient suffered subarachnoid hemorrhage.

Aneurysms were located predominantly intradural in the ophthalmic and precommunicant part of the internal carotid artery. Aneurysms were mostly of unknown etiology. Only in patient No. 9 the etiology was known. She underwent radiation therapy of the meningioma of the cavernous sinus (Table 1).

\section{Anticoagulant protocols and drugs}

The patients began with the preoperative preparation 5 days before hospitalization with $75 \mathrm{mg}$ clopidogrel p.o. a day and $100 \mathrm{mg}$ acetylsalicylic acid p.o. a day. Before the procedure the prothrombin time, using a standard method with a VerifyNow meter (Accumetrics, San Diego, USA) and a standardized lab test for acetylsalicylic acid and clopidogrel, was measured ensuring that the patient is not resistant to clopidogrel therapy. ${ }^{12,13}$

After the introduction of a guiding catheter an intravenous bolus of heparin, 5000 units, was administrated, also taking into account the weight of the patient. Heparinization continued for 24 hours after the procedure. Patients were hospitalized for one or two days and discharged with antithrombotic and antiplatelet protection with a daily dose of $75 \mathrm{mg}$ clopidogrel for 6 months and $100 \mathrm{mg}$ acetylsalicylic acid for a period of one year. Before hospitalization and before discharge, the neurological examination was performed. The neurological examination was also performed prior to the control MR angiography.

To prevent perioperative vasospasm $2 \mathrm{ml}(0.2$ $\mathrm{mg} / \mathrm{ml}$ ) nimodipine diluted in $10 \mathrm{ml}$ physiological saline were administrated i.a. in all cases prior to the procedure. In patients with large aneurysms corticosteroids for the duration of 48 hours were prescribed for the prevention of the inflammatory response after the embolization.

\section{Methods and the procedure}

The placement of the flow diverting device is performed under general anesthesia, which ensures that the patient is perfectly calm during the procedure. In our institution we have a single-plain C-arm system Axiom Artis (Siemens, Germany).

We use a classical approach using the Seldinger technique. After the puncture of the femoral artery we introduce the angiographic catheter fist into the femoral artery and then via the aorta and the aortic arch into the common carotid artery. A detailed angiographic processing of the aneurysms with preoperative angiography in typical projections, rotating three-dimensional subtraction angiography with computerized data processing, construction and reconstruction of an aneurysm in the head-up display technique is performed (Figure 1). This al- 
lows us detailed measurements of the aneurysm. It also helps us to select working projections and to assess the dimensions of the stent. Then, using an exchange wire $265 \mathrm{~cm}$ in length, a long vascular introducer sheath Destination (Terumo, USA) is placed into the common carotid artery. Through the introducer sheath a soft $6 \mathrm{~F}$ guiding catheter Neuron 53 (Penumbra, USA) is introduced into the internal carotid artery at the level of the skull base. The Neuron 53 (Penumbra, USA) catheter enables us good maneuverability and is the new generation of guiding catheters, which can be introduced even through the cavernous part of the internal carotid artery all the way to its bifurcation.

5000 units of heparin bolus i.a. are administered followed by the passage of the neck of the aneurysm with Marxsmann microcatheter (ev3, Covidien, USA) with the help of the micro guide wire. The guide wire is than removed and the Pipeline stent with the radiopaque pusher wire (ev3, Covidien, USA) is introduced. Pusher wire, serving now as a guide wire, is introduced in the initial segment of the middle cerebral artery (M1), in order to achieve an adequate stability of the catheter. A control angiography through the guiding catheter is performed to control the position of the stent in relation to the neck of the aneurysm. Release of the stent is performed by extraction of the guiding catheter and the simultaneous introduction of the pusher wire. The stent must open completely and it must fit the vessel wall tightly (Figure 2). Then the pusher wire can be extracted and the final angiography is performed, to check the position of the stent, if the stent is completely opened and fits the vessel wall tightly. Particular attention should be paid to the possible occurrence of dissection at the start and the end of the stent. Care should be taken that the stent fits the vessel wall perfectly, otherwise clotting of blood between the stent and the vessel wall can occur, which may lead to thrombus formation, and the closure of the stent lumen (Figure 3).

After the procedure a CT examination was performed to exclude any intracranial bleeding due to vessel wall injury, which may occur because of the manipulation of the guiding wires.

\section{Evaluation of procedure success}

Closing of the aneurysm is a long process and therefore angiography after stent placement does not say much about the effectiveness of the intervention. The process of stagnation of blood and thrombosis of the aneurysms may persist for sev-

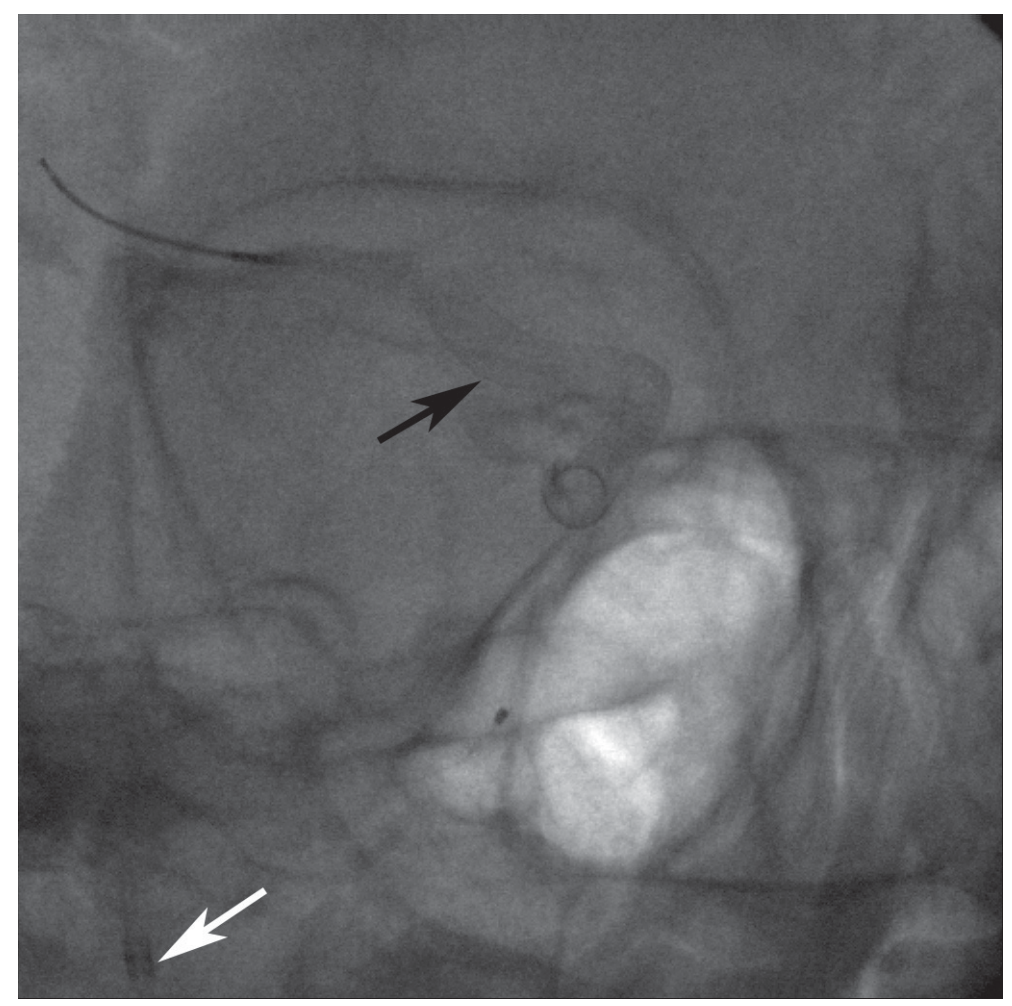

FIGURE 2. The position of the flow diverter stent on the native radiogram is indicated by the black arrow. The white arrow indicates the tip of the guiding catheter.

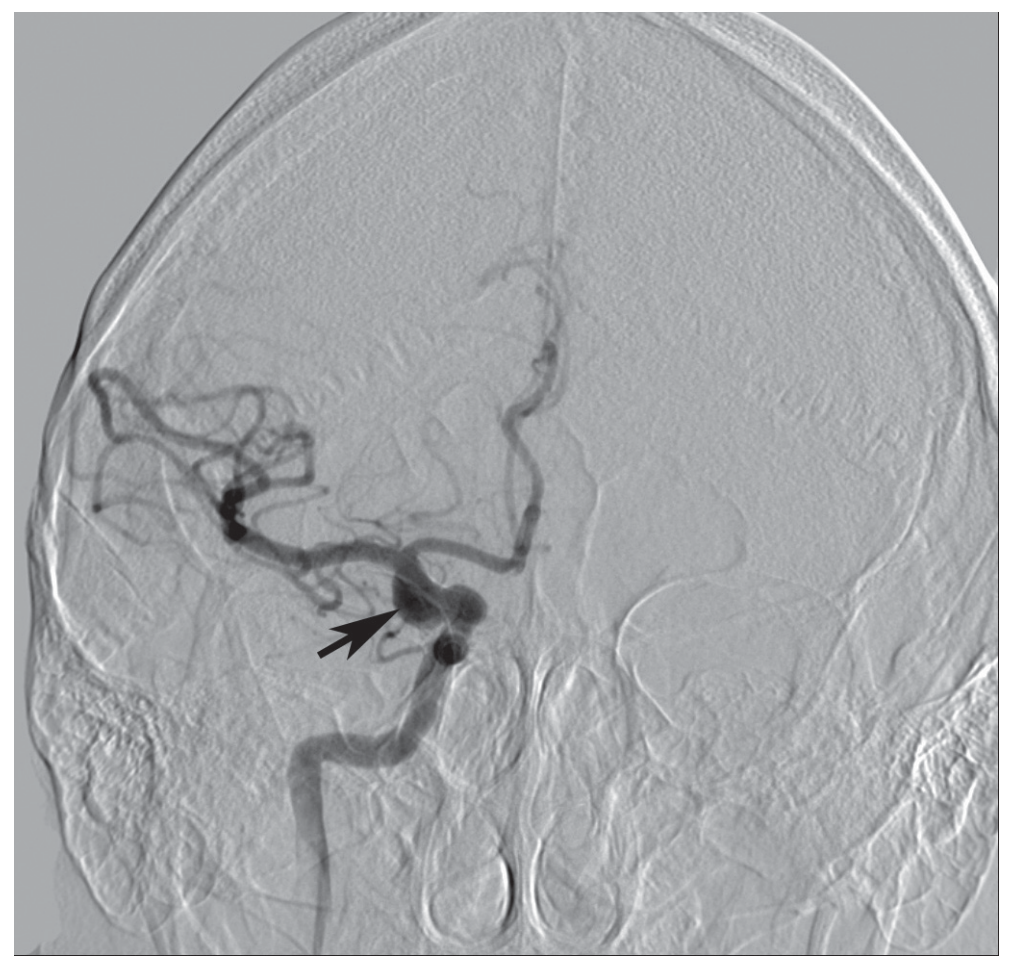

FIGURE 3. Control DSA direct after the positioning of the flow diverter stent shows some residual filling of the aneurism (arrow). The stent fits the vessel wall perfectly. 


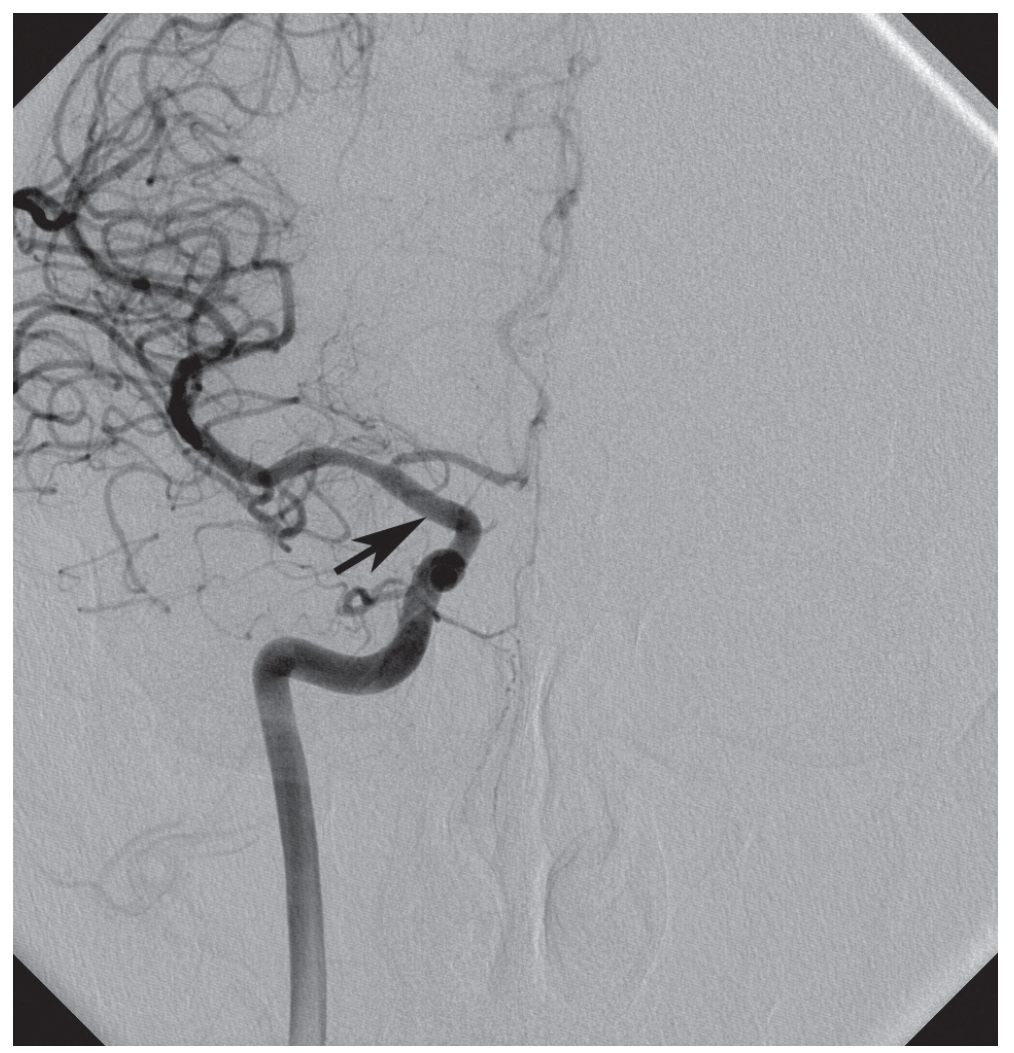

FIGURE 4. Control DSA after 12 months shows complete thrombosis of the aneurism (arrow) and good patency of the distal arteries.

eral weeks or months after placing the flow diverting stent. In the case of endovascular aneurysm closure with coils residual filling of the aneurysm, after Roy-Raymond scale, is a bad result. Residual filling of the aneurysm in the case of flow diverting stent placement however is acceptable and even desirable. ${ }^{14}$

Traditional evaluating scales, such as the RoyRaymond scale, which are used for evaluating the success of the procedure in the case of endovascular and surgical aneurysm treatment, are unsuitable for evaluation of flow diverting stent procedure success. According to Roy-Raymond scale residual filling of the aneurysm after the procedure is undesirable. In the case of flow diverting stent placement however such a result, immediately after the procedure, is expected. Therefore, a new scale, named after O'Kelly and Marotta was made. ${ }^{15}$ This scale consists of two parameters, which correspond to the mechanism of flow diverting stent action in protecting the aneurysm:

Reduced aneurysm filling (filling rate), which corresponds to the anatomical aspect.

Accelerated blood retention within the aneurysm (retention rate) in the arterial, parenchymal, and venous phase, which corresponds to a more dynamic and physiological parameter.

All of the patients have had MRA (and axial T2) between 6-12 month after the procedure to asses silent ischemic lesions and aneurysm exclusion.

To assess only stent patency and aneurysm exclusion or late reperfusion we performed either computed tomography angiography (CTA) or magnetic resonance angiography (MRA) first during 3-6 month period, second 6-12 month period and third 24 month period after the procedure.

\section{Results}

Between 2010 and 2014 we treated 15 patients with flow diverting device. In 14 patients we used one stent and in one patient it was necessary to use two stents, applying a telescope technique in which the second stent works like an extension of the first. There were no serious technical complications during the procedure in none of the patients. In three patients there was need of using a balloon for dilation of the stent to achieve tight fit to the arterial wall.

Control angiography also showed exclusion of the aneurysm from the circulation and a normal patency of the stent (Figure 4, Figure 5). In three patients with multiple aneurysms, which were covered with a Pipeline (ev3, Covidien, USA), all the aneurysms were excluded from the circulation.

All control examinations, except of two, were within normal limits. In case of one patient there were ischemic changes in the area of right nucleus lentiformis, however there were no clinically manifestations. In another patient some residual filling of the aneurysm on the 12 months MRI angiography control was observed, which was caused by flow diverter shrinkage.

The symptoms that patients had prior the procedure mostly disappeared. One patient had double images prior the procedure and was symptomless three days after the procedure. Later double vision reoccurred and lasted for 12 months. In patients in whom the stent covered the ophthalmic artery no deterioration of the vision was observed, probably due to the suction effect of the artery. ${ }^{16}$ Patients who had headaches prior to the procedure were without symptoms after the procedure. (Figure 5)

\section{Discussion}

Large and giant aneurysms represent a challenge for both surgical and endovascular approaches. 
Such aneurysms often present with mass effect and corresponding compression syndrome on the neighboring neural tissue. Therefore, the goal of treatment is not only to prevent rupture but also to reduce the pulsating mass and eliminate the associated mass effect. Unfortunately, this goal is difficult to achieve by conventional endovascular techniques. ${ }^{17}$

For the endovascular treatment of cerebral aneurysms, a number of options are available. We can use bare coils or coils covered with hydrogel which are 2- or 3D shaped. We can also use a balloon or a stent for remodeling the neck of the aneurysm in combination with coil embolization. The use of stents and coils can be successfully used in treatment of wide neck aneurysms. There is also a possibility of using a liquid polymer with a supporting balloon. Currently no drug eluting stents are available for treatment of aneurysms. The method of using stents and coil deployment after stent placing showed good short-term results, but the long-term results were not encouraging because of a high recanalization rate. This has been found in approximately $20 \% .^{3-6}$

With the development of technology and the development of new, much more flexible, stents with very densely braided mesh a new technique for treating these aneurysms emerged. Wider use of flow diverting stents occurred after 2010, both in Europe and in the USA. Definitive indications for the flow diverting stent usage are not yet established, but mainly it is used on randomly discovered, complex aneurysms of the internal carotid artery in both extracranial and intracranial part of the carotid artery and its branches. It is often used on abnormalities of the artery walls, which cover a longer segment of the vessel and not just saccular aneurysm as the simplest form of the lesion. ${ }^{7,8}$

Concerns that may arise with the use of flow diverting stents are the formation of thrombus within the aneurysm and its fibrous transformation. Review of literature and experience in placing the flow diverting stents in the treatment of the aneurysms of the abdominal aorta show that after the formation of the thrombus, especially in giant aneurysms, the thrombus can get infected causing swelling and headaches. The extent of these symptoms is often related to the size of the aneurysm. The focus of the inflammation is in the thrombus within the aneurysm. ${ }^{18}$ In favor of this hypothesis are a number of published cases with extensive edema around a giant aneurysm before the treatment of the aneurysm. Inflammatory changes may also be present in the wall of small aneurysms,
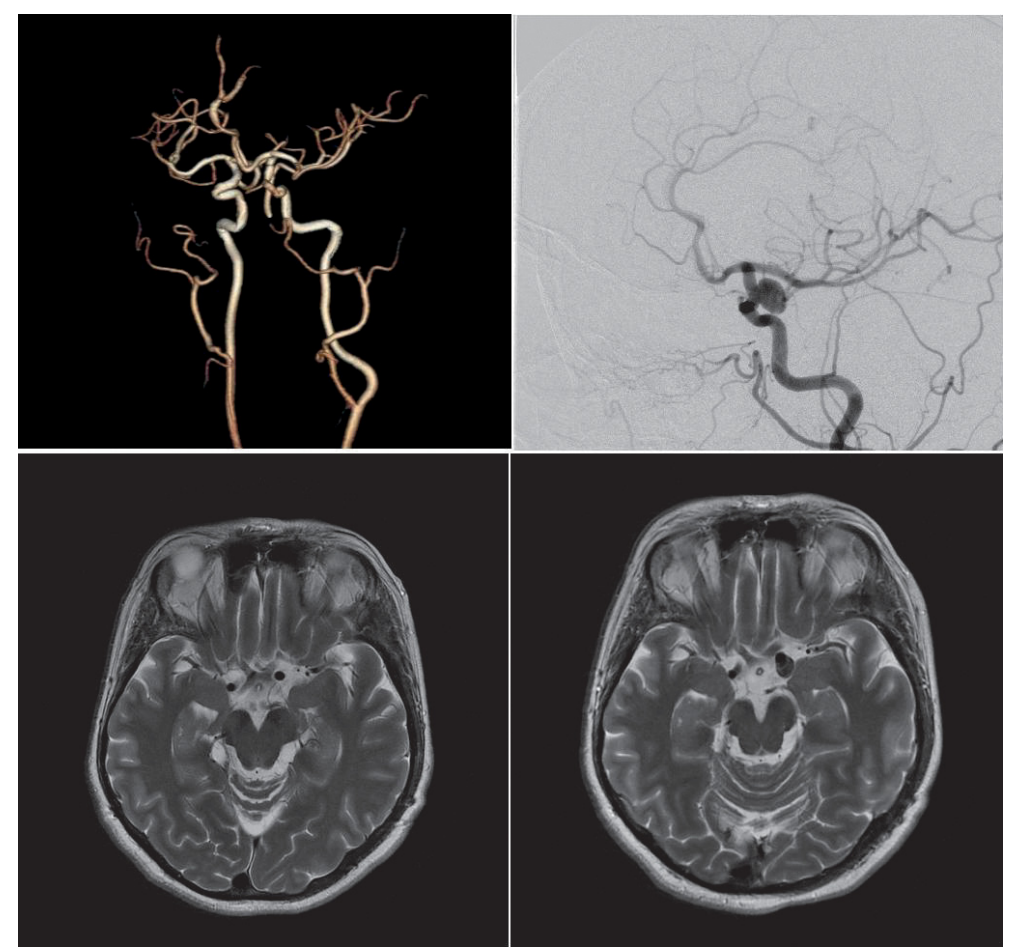

FIGURE 5. Control MR after 12 months shows complete thrombosis of the aneurism (arrow) and aneurysm collapse following flow diverter treatment.

but these changes usually do not cause complications and can heal by themselves or remain dormant. It appears that the physiology of large and giant aneurysms by itself cause inflammation. Histopathological studies have shown that the wall of the aneurysm, which is covered with a thick layer of thrombus, is thinner with less smooth muscle cells, less elastin and the increased number of inflammatory cells in comparison with the aneurysm with the thinner thrombus. ${ }^{19,20}$

Another problem that can occur, are the arteries that must be covered during the placement of the stent. The major problem is the ophthalmic artery. Here the placement of the stent can cause an occlusion. However, in all our patients, in which deceased filling of the ophthalmic artery was observed, additional anastomoses through external carotid artery appeared. Despite impeding flow to the ophthalmic artery using flowdiverter this did not result in clinical sequelae in the current study which correlates with Durst CR at all study. ${ }^{21}$ The obstruction of the artery is prevented by the vacuum effect that can be best observed in the case of anterior cerebral artery covering, where after the stent placement no obstruction of blood flow is observed. The vacuum effect can be the main cause of prolonged thrombus formation. ${ }^{22}$ 
Technical barrier to successful procedure is a phenomenon of vasospasm. Therefore, initial bolus of nimodipine followed by nimodipine drip infusion during the procedure is obligatory.

Permanent stent patency does not represent a big problem. Although the treatment of these aneurysms is complicated, the stents are placed in the part of the artery, which shows no intraluminal atherosclerotic changes. At the same time, it is a relatively large artery.

There is also the question of reducing the size of the aneurysm due to thrombosis and subsequent fibrotic transformation of the thrombus after stent placement. Based on the clinical picture, we believe that this effect occurs, although indirectly (Figure 5).

In our study none of the procedural and periprocedural complications were observed. 6 months after the procedure, control CT or MR angiography showed in almost all cases exclusion of the aneurysm from the circulation and normal blood flow in the treated artery. Neurological status six months after the procedure was normal in all patients.

\section{Conclusions}

Initial clinical results of our single center series with flow diverter device Pipeline are encouraging. We had no technical difficulties so far. All aneurysms were excluded from circulation. For the full implementation of the method however, further studies are required. Special attention should be paid to the impact of the stent on the covered arteries.

\section{References}

1. Fernandez Zubilaga A, Guglielmi G, Vinuela F, Duckwiler GR. Endovascular occlusion of intracranial aneurysms with electrolitically detachable coils: correlation of aneurysms neck size and treatment results. Am J Neuroradiol 1994; 15: 815-20.

2. International Subarachnoid Aneurysm Trial (ISAT) Collaborative group. ISAT of neurosurgical clipping versus endovascular coiling in 2143 patients with ruptured intracranial aneurysms: a randomized trial. Lancet 2002; 360: 1267-74.

3. Sluzewski M, van Rooij WJ, Rinkel GJ, Wijnalda D. Endovscular treatment of ruptured intracranial aneurysms with detachable coils: long-term clinical and serial angiographic results. Radiology 2003; 227: 720-4.

4. Golshani K, Ferrel A, Lessne M, Shah P, Chowdhary A, Alexander MJ, et al. Stent-assisted coil embolization of ruptured intracranial aneurysms: A retrospective multicenter review. Surg Neurol Int 2012; 3: 84.

5. Chalouhi N, Witte S, Penn DL, Soni P, Starke RM, Jabbour P, et al. Singlecenter experience with balloon-assisted coil embolization of intracranial aneurysms: Safety, efficacy and indications. Clin Neurol Neurosurg 2013; 73: $282-8$
6. Cekirge HS, Saatci I, Ozturk MH, Cil B, Arat A, Mawad M, et al. Late angiographic and clinical follow-up results of 100 consecutive aneurysms treated with Onyx reconstruction: largest single-center experience. Neuroradiology 2006; 48: 113-26

7. Bergauer A, Kobilica N, Štirn B, Milotič F, Mrdža B, Tetičkovič E, et al. Internal carotid artery plication following carotid endarterectomy: our experience. Acta medico-biotechnica 2010; 3: 20-8

8. Fiorella D, Woo HH, Albuquerque FC, Nelson PK. Definitive reconstruction of circumferential, fusiform intracranial aneurysms with the pipeline embolization device. Neurosurgery 2008; 62: 1115-20.

9. Kan P, Siddiqui AH, Veznedaroglu E, Liebman KM, Binning MJ, Dumont TM, et al. Early Postmarket results after treatment of intracranial aneurysms with the Pipeline embolization device: a U.S. multicenter experience. Neurosurgery 2012; 71: 1080-7.

10. Rasskazoff S, Silvaggio J, Brouwe PA, Kaufmann A, Nistor A, lancu D. Endovascular treatment of ruptured blood blisterlike aneurysm with a folow diverting stent. Interventional Neuroradiol 2010; 16: 255-8.

11. Siddiqui AH, Kan P, Abla AA, Hopkins LN, Levy El. Complications after treatment with pipeline embolization for giant distal intracranial aneurysms with or without coil embolization. Neurosurgery 2012; 71: E509-513.

12. Drazin D, Choulakian A, Nunjo M, Konbluth P, Alexander MJ. Body weight: a risk factor for subtherapeutic antithrombotic therapy in neurovascular stenting. J Neurointervent Surg 2011; 3: 177-81.

13. Pandya DJ, Fitzsimmons BF, Wolfe TJ, Hussain SI, Lynch JR, OrtegaGutierrez S, et al. Maesurment of antiplatelet inhibition durin inteventional procedures: the effect of antithrombotic duration and loading dose. J Neuroimaging 2010; 20: 64-9.

14. Raymond J, Guilbert F, Weill A, Georganos SA, Juravsky L, Lambert A, et al. Long-term angiographic recurrences after selective endovascular treatment of aneurysms with detechable coils. Stroke 2003; 34: 1398-403.

15. O'Kelly CJ, Krings T, Fiorella D, Marotta MR. A novel grading scale for the angiografic assesment of intracarnial aneurysms treated using flow divertting stents. Interv Neuroradiol 2010; 16: 133-7.

16. Puffer RC, Kallmes DF, Cloft HJ, Lanzino G. Patency of the ophthalmic artery after flow diversion treatment of paraclinoid aneurysms. J Neurosurg 2012; 116: 892-6.

17. Szikora I, Marosfoi M, Salomváry B, Berentei Z, Gubucz I. Resolution of mass effect and compression symptoms following endoluminal flow diversion for the treatment of intracranial aneurysms. Am J Neuroradiol 2013; 34: 935-9.

18. Kazi M, Thyberg J, Religa P, Roy J, Eriksson P, Hedin U, et al. Influence of intraluminal thrombus on structural and cellular composition of abdominal aortic aneurysm wall. J Vasc Surg 2003; 38: 1283-92.

19. Wang DH, Makaroum M, Webster MV, Vorp DA. Mechanical properties and micro structure of intraluminal thrombus from abdominal aortic aneurysm. J Biomech Eng 2001; 123: 536-9.

20. Vorp DA, Lee PC, Wang DH, Makaroun MS, Nemoto EM, Ogawa S, et al. Association of intraluminal thrombus in abdominal aortic aneurysm with local hypoxia and wall weakening. J Vasc Surg 2001; 34: 291-9.

21. Durst CR, Starke RM, Clopton D, Hixson HR, Schmitt PJ, Gingras JM, et al. Endovascular treatment of ophthalmic artery aneurysms: ophthalmic artery patency following flow diversion versus coil embolization. J Neurointerv Surg 2016; 8: 919-22

22. Hampton T, Walsh D, Tolias C, Fiorella D. Mural destabilization after aneurysm treatment with a flow-diverting device: a report of two cases. $J$ Neurointervent Surg 2011; 3: 167-71. 